\title{
Erratum to: Encapsulated Hsp70 decreases endotoxin-induced production of ROS and TNF $\alpha$ in human phagocytes
}

\author{
M. M. Yurinskaya ${ }^{1,2}$ • O. Yu. Kochetkova ${ }^{2,3}$ - L. I. Shabarchina ${ }^{3}$ - O. Yu. Antonova ${ }^{2}$. \\ A. V. Suslikov ${ }^{4}$ • M. B. Evgen'ev ${ }^{1,2}$ • M. G. Vinokurov ${ }^{2}$
}

Published online: 28 February 2017

(C) Cell Stress Society International 2017

Erratum to: Cell Stress and Chaperones (2017) 22:163-171

DOI 10.1007/s12192-016-0743-z

Due to an unfortunate turn of events, the first- and surnames of all authors were transposed in the original publication. The correct representation of the authors' names and their affiliations are listed in this erratum.

The online version of the original article can be found at http://dx.doi. org/10.1007/s12192-016-0743-z.

M. B. Evgen'ev

misha672011@yahoo.com

1 Engelhardt Institute of Molecular Biology, Russian Academy of Sciences, Vavilov Str. 32, Moscow, Russian Federation 119991

2 Institute of Cell Biophysics, Russian Academy of Science, Institutskaya Str. 3, Pushchino, Moscow Region, Russian Federation 142290

3 Institute of Theoretical and Experimental Biophysics, Russian Academy of Sciences, Institutskaya Str. 3, Pushchino, Moscow Region, Russian Federation 142290

4 Hospital of the Pushchino Research Center, Institutskaya Str. 1, Pushchino, Moscow Region, Russian Federation 142290 